\section{Production of Sinus Arrest by Lignocaine}

\section{CARL TH. LIPPESTAD, KOLBJØRN FORFANG}

\section{British Medical fournal, 1971, 1, 537}

In recent years lignocaine has become increasingly important as an antiarrhythmic drug, both in arrhythmias occurring after acute myocardial infarction and in those related to cardiac surgery. Its greatest effect is seen on ventricular extrasystoles and in ventricular tachycardia (Hitchcock and Keown, 1959; Frieden, 1965). Not much has been said about the effect on the sinus node, but its frequency of discharge is reported to be little reduced with ordinary dosages (1-4 mg/kg) (Harrison et al., 1963; Hayes et al., 1967; Killip, 1968). In animal experiments it is difficult to produce sinoatrial block with lignocaine (Hitchcock and Keown, 1959).

The effect of lignocaine in the "sick sinus syndrome" has not been reported previously. This condition is described by Lown (1967) as a defect in elaboration or conduction of sinus impulses characterized by chaotic atrial activity, changing P-wave contour, and bradycardia, interspersed with multiple and recurrent ectopic beats, with runs of atrial and nodal tachycardia. Accordingly, the clinical symptoms are often multiple and changing, and result from hypoperfusion of vital organs (Ferrer, 1968). The sick sinus syndrome can be produced by a variety of pathological lesions and functional disturbances which lead to sinus node dysfunction (Marton and Lippestad, 1969).

Theoretically it is possible that lignocaine has the same effect as many other drugs-that is, of aggravating an injury on the sinus node or, alternatively, revealing a latent injury (James, 1961). The following report illustrates this point.

\section{Case Report}

A woman aged 77 was admitted to hospital on 15 May 1968 because of periodic dyspnoea of one year's duration. She had not been digitalized, but had been treated with trichlormethiazide 2 mg daily. During the last two or three weeks before admission she had suffered from palpitations and increasing attacks of dyspnoea. Electrocardiograms taken on 21 and 23 May showed signs of sick sinus node (Fig. 1). No signs of previous myocardial infarction or

FIG. 1-A, E.C.G. taken 21 May 1968 (lead II, paper speed $50 \mathrm{~mm} / \mathrm{sec}$ )
showing sudden cessation of sinus node function with atrioventricular
junctional escape beats. B, Recording made 23 May (lead and paper speed as
for A) showing sinus bradycardia with atrioventricular junctional and
possible atrial escapes.

any other myocardial disease were found. Serum electrolytes were normal.

She was initially treated with atropine for the bradycardia and congestive failure, but without effect. During subsequent treatment

Oslo University Clinic, Medical Department A, Aker Hospital, Oslo 5, Norway

CARL TH. LIPPESTAD, M.D.

KOLBJðRN FORFANG, M.D. with isoprenaline various forms of supraventricular tachycardias were observed. Her attacks of dyspnoea stopped after the administration of diuretics. Digitalis was not given. On 27 May electrocardiographic recordings showed sinus rhythm alternating with ectopic atrial rhythm (Fig. 2 A). At that time the doctor on duty gave her $50 \mathrm{mg}$ of lignocaine intravenously. Two minutes later the sinus node activity gradually faded, and within 10 minutes had ceased completely. In addition, there was an exit block in the nodal pacemaker (Fig. 2 B). The irregular ectopic

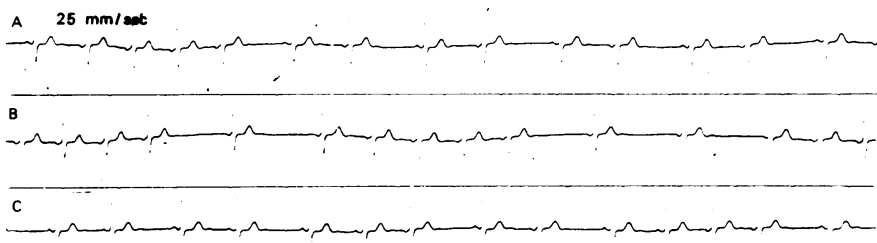

FIG. 2-A, E.C.G. taken 27 May 1968 (monitor lead, paper speed $25 \mathrm{~mm} / \mathrm{sec}$ ) immediately before lignocaine was given, showing sinus rhythm alternating with ectopic atrial rhythm (same focus as QRS complexes 3 and 4 in Fig. 1 B?). $B$, Recording made ten minutes after administration of lignocaine, showing complete cessation of sinus node function. Ectopic rhythm is irregular and slow. C, Recording made 30 minutes after administration of lignocaine, and seven minutes after atropine $0.6 \mathrm{mg}$ intravenously, showing re-establishment of sinus activity.

rhythm persisted until $0.6 \mathrm{mg}$ of atropine was given intravenously 23 minutes after the lignocaine injection. The ectopic rhythm then became more regular and sinus activity was re-established (Fig. 2 C).

\section{Comment}

In retrospect lignocaine should not have been used in this case. Nevertheless, the effect of lignocaine on the sinus node, is of interest and has not previously been reported. The mechanism is unknown, but it is possible that lignocaine in the sick sinus node may depress the depolarization of the impulse-creating fibres, so that they never reach the potential necessary to release the pacemaker impulse. Or the explanation may be atrial non-responsiveness due to subthreshold sinus impulse (Scherf, 1969). Our knowledge acquired in recent years about the sick sinus node may therefore be important in the treatment of arrhythmias. Several workers (James, 1966; Lown, 1967; Marton and Lippestad, 1969; Storstein, 1969) have called attention to this problem in connexion with reversion of atrial fibrillation. As stated by James (1962), the "overzealous therapist may abolish the arrhythmia only to find the sinus node unable to take over." Our observations indicate that lignocaine (and probably also agents with a similar action, like procainamide and quinidine) may abolish the function of the sinus node when that node is already injured.

Requests for reprints should be addressed to Dr. Carl Th Lippestad, Medical Department A, Aker Hospital, Oslo 5, Norway.

\section{References}

Ferrer, M. I. (1968). Fournal of the American Medical Association, 206, 645 Frieden, J. (1965). American Heart Fournal, 70, 713.

Harrison, D. C., Sprouse, J. H., and Morrow, A. G. (1963). Circulation, 28, 486

Hayes, J. G., Ettinger, E., Wanat, F. E., and Killip, T. (1967). Circulation, 36, Suppl. No. 2, p. 137.

Hitchcock, P., and Keown, K. K. (1959). Southern Medical fournal, 52, 702 James, T. N. (1961). Circulation, 24, 761.

Tames, T. N. (1962). Archives of Internal Medicine, 110, 305.

James, T. N. (1966). Annals of Internal Medicine, 65, 28.

Killip, T. (1968). In Acute Myocardial Infarction, ed. D. G. Julian and M. F. Oliver, D. 106. Edinburgh, Livingstone.

Lown, B. (1967). British Heart fournal, 29, 469

Marton, P. F., and Lippestad, C. Th. (1969). Nordisk, Medicin, 81, 33.

Scherf, D. (1969). American Fournal of Cardiology, 23, 769.

Storstein, O. (1969). Nordisk Medicin, 81, 51. 